\title{
Doctor-patient differences in risk and time preferences: A field experiment
}

\author{
Matteo M. Galizzi ${ }^{\mathrm{a}, \mathrm{b}, *}$, Marisa Miraldo ${ }^{\mathrm{b}, \mathrm{c}}$, Charitini Stavropoulou ${ }^{\mathrm{d}}$, Marjon van der Pol ${ }^{\mathrm{e}}$ \\ a Department of Social Policy, Behavioural Research Lab, LSE Health, London School of Economics, Old 2.35 Old Building, Houghton Street, London WC2A \\ $2 A E, U K$ \\ ${ }^{\mathrm{b}}$ École d'Économie de Paris, Hospinnomics, Paris School of Economics, Hôtel-Dieu, 1, Parvis de Notre-Dame, Bâtiment B1, $5^{\circ}$ étage, 75004 Paris, France \\ ${ }^{c}$ Management Group, Imperial College Business School, South Kensington Campus, London SW7 2AZ, UK \\ d School of Health Sciences, City, University of London, Northampton Square, London EC1V OHB, UK \\ ${ }^{\mathrm{e}}$ Health Economics Research Unit, University of Aberdeen, Polwarth Building, Foresterhill, Aberdeen AB25 2ZD, UK
}

\section{A R T I C L E I N F O}

\section{Article history:}

Received 2 May 2015

Received in revised form 4 October 2016

Accepted 7 October 2016

Available online 19 October 2016

\section{JEL classification:}

D91

D03

C93

\section{Keywords:}

Field experiments

Risk aversion

Impatience

Doctor-patient relationship

Structural estimation

\begin{abstract}
A B S T R A C T
We conduct a framed field experiment among patients and doctors to test whether the two groups have similar risk and time preferences. We elicit risk and time preferences using multiple price list tests and their adaptations to the healthcare context. Risk and time preferences are compared in terms of switching points in the tests and the structurally estimated behavioural parameters. We find that doctors and patients significantly differ in their time preferences: doctors discount future outcomes less heavily than patients. We find no evidence that doctors and patients systematically differ in their risk preferences in the healthcare domain.
\end{abstract}

(C) 2016 Elsevier B.V. All rights reserved.

\section{Introduction}

The doctor-patient interaction is generally modelled as an agency relationship (Iizuka, 2007; McGuire, 2000; Stavropoulou, 2012). Due to information asymmetry, the doctor acts as an agent making decisions on behalf of the patient. In a perfect agency model, doctors' decisions should reflect patients' preferences. In the case of health decisions patients' risk preferences - the desire for taking a gamble - and time preferences - the degree to which the present is valued more than the future - are of particular interest (Bradford et al., 2014; Bradford, 2010; Cairns and Van der Pol, 1997; Dolan and Gudex, 1995; Gafni and Torrance, 1984; Gurmankin et al., 2002; van der Pol and Cairns, 2001, 2002, 2008; Van Der Pol, 2011; Van Der Pol and Cairns, 1999). The agency relationship may not be perfect as

\footnotetext{
* Corresponding author. Department of Social Policy, Behavioural Research Lab, LSE Health, London School of Economics, Old 2.35 Old Building, Houghton Street, London WC2A 2AE, UK. Fax: +44 (0)20 79557345.

E-mail addresses: m.m.galizzi@lse.ac.uk (M.M. Galizzi),m.miraldo@imperial.ac.uk (M. Miraldo), c.stavropoulou@city.ac.uk (C. Stavropoulou), m.vanderpol@abdn.ac.uk (M. van der Pol)
}

doctors cannot easily observe or interpret patients' preferences (Fagerlin et al., 2011; Say and Thomson, 2003; Ubel et al., 2011). If doctors make decisions on the basis of their own rather than patients' preferences, it is important to understand whether the two parties have similar preferences for risk and time.

The importance of risk and time preferences in medical decisionmaking has been extensively discussed in the medical literature. From screening tests (Edwards et al., 2006) and general practice (Edwards et al., 2005) to specialist visits for cardiovascular conditions (Waldron et al., 2010), almost every doctor-patient consultation involves a discussion of the trade-offs between risks and benefits of treatments over time before a treatment decision is made (Zikmund-Fisher et al., 2004). Evidence suggests that doctors' risk and time preferences affect treatment decisions (Allison et al., 1998; Fiscella et al., 2000; Franks et al., 2000; Holtgrave et al., 1991); and that patients' risk and time preferences have an impact on the uptake of vaccinations, preventive care, and medical tests (Axon et al., 2009; Bradford, 2010; Bradford et al., 2010; Chapman and Coups, 1999; Picone et al., 2004) and on treatment adherence (Brandt and Dickinson, 2013; Chapman et al., 2001). This means that if doctors and patients vary in terms of risk and time preferences and doctors 
cannot readily observe these differences, doctors may recommend treatments that are not optimal given patients' risk and time preferences, which may result in lower treatment adherence. Treatment adherence is of major concern and has been shown to vary across individuals (WHO, 2003). Some of this variation may be due to differences in risk and time preferences between doctors and patients. Better matching of doctors to patients may therefore improve health outcomes through better treatment allocation and adherence.

Although the medical literature provides broad evidence on the key role of doctor-patient communication on healthcare decisions (Bjerrum et al., 2002; Dudley, 2001; Fagerlin et al., 2005a, 2005b, 2005c; Kipp et al., 2013; Ortendahl and Fries, 2006; Peele et al., 2005), there is little evidence on whether patients and their doctors have similar or different risk and time preferences. This gap in the evidence is largely due to the lack of primary data that directly measure, in a quantitatively comparable way, risk and time preferences across patients and doctors.

Moreover, there is now broad evidence that risk and time preferences are largely domain-specific (Attema, 2012; Barseghyan et al., 2011; Blais and Weber, 2006; Bleichrodt and Johannesson, 2001; Bleichrodt et al., 1997; Butler et al., 2012; Cairns, 1994; Chapman, 1996; Chapman and Elstein, 1995; Cubitt and Read, 2007; Einav et al., 2010; Finucane et al., 2000; Galizzi et al., 2016; Hanoch et al., 2006; Hardisty and Weber, 2009; Hershey and Schoemaker, 1980; Jackson et al., 1972; MacCrimmon and Wehrung, 1990; Prosser and Wittenberg, 2007; Viscusi and Evans, 1990; Weber et al., 2002). Even within the same health domain, preferences vary across different contexts (Bradford et al., 2014; Butler et al., 2012; Harrison et al., 2005a; Szrek et al., 2012; van der Pol and Ruggeri, 2008). It is possible, therefore, that doctors' and patients' healthcare decisions are explained not only by their risk and time preferences for monetary outcomes, but also (and perhaps more closely) by risk and time preferences for healthcare outcomes. No secondary data, however, currently exist that directly elicit health-related risk and time preferences for patients and doctors (Bradford, 2010).

In this article we attempt to fill this gap by explicitly investigating whether patients and their matched doctors in natural clinical settings have similar risk and time preferences for healthcare outcomes. As a robustness check, we also measure risk and time preferences in a closely comparable financial context. To the best of our knowledge, ours is the first attempt to systematically look at differences and similarities of risk and time preferences across doctors and patients in a real healthcare setting.

We conduct a 'framed field experiment' based on Harrison and List (2004) (an 'extra-lab' experiment according to Charness et al., 2013b). Field experiments are increasingly employed in exploring preferences (Andersen et al., 2008a, 2008b, 2014; Charness et al., 2013a; Harrison et al., 2007; Sutter et al., 2011), and in comparing them across different groups of subjects (Croson and Gneezy, 2009; Harrison et al., 2009; Masclet et al., 2009). In our field experiment we measure patients' and doctors' risk and time preferences by adapting the multiple price list (MPL) tests proposed by Holt and Laury (2002) and Tanaka et al. (2010), respectively, to the healthcare context (Galizzi et al., 2016). In order to address any issue that can potentially arise from framing and domain-specificity in preference elicitation, we also measure patients' and doctors' risk and time preferences using the same MPL tests but in a closely comparable financial context.

We have three main results. First, there is a significant difference in time preferences between patients and their matched doctors, with doctors discounting future health gains and financial outcomes less heavily than patients. Second, we find no systematic difference in risk preferences in the healthcare domain between patients and doctors: in our sample both patients and their matched doctors are mildly, but significantly, risk averse. Third, doctors and patients have significantly different risk preferences in the finance domain: whilst doctors are risk averse, patients are risk neutral.
The rest of the article is organised as follows. Section 2 contains a brief description of the methods whilst Section 3 reports the main results. Section 4 discusses the main findings in the context of the literature, whilst the last section briefly concludes.

\section{Methods}

\subsection{Study design}

We conducted a field experiment among patients and doctors in a university hospital in Athens (Laiko Hospital), Greece, in four waves between September 2010 and November 2011. ${ }^{1}$ Patients were asked to complete a questionnaire (Online Appendix A1) whilst they were waiting in the outpatients' clinics to see their doctors. The questionnaire was completed in the presence of a research assistant who explained the questions and was available for assistance during the completion of the questionnaire. The patients' doctors were also invited to take part in the study by completing a similar questionnaire. The outpatient clinics were pathology, cardiology, gynaecology, haematology, surgery, endocrinology, orthopaedics, urology, gastroenterology, nephrology, rheumatology, ophthalmology, and otolaryngology. Patients who attend the outpatient clinics are seen by the first available doctor. They are therefore randomly assigned to their doctors. We obtained questionnaire data for 300 patients and 67 doctors. Not all patients could be matched to the doctor they saw for two reasons. First, patients did not know beforehand which doctor they would see, and some patients refused to answer further questions when leaving the clinic. Second, some doctors did not complete the questionnaire. A total of 144 patients ( $48 \%$ of patients) could be matched to their doctors.

The study was approved by the hospital's Research Ethics Board on 6 August 2010 (protocol number ES 462).

\subsection{Questionnaire and variables}

The questionnaire included a number of socio-demographic questions, such as the respondents' age (Age), gender (Female), marital status (Married), education level (Educ), perception of their current financial situation (FinConstr), and whether they have children or not (Children). Patients were also asked about their health status, both by reporting their self-assessed health $(S A H)$ and whether or not they had a chronic condition (Chronic). A full description of the variables in the questionnaire can be found in Appendix A.

\subsubsection{Risk preferences}

Risk preferences were measured using an adaptation of the Holt and Laury (2002) MPL test to the healthcare context (Galizzi et al., 2016). The MPL method is one of the most widely used incentivecompatible tests in experimental economics to measure risk preferences for monetary outcomes (Charness et al., 2013a). Subjects are presented with a series of choices between two lotteries ( $A$ and $B$ ). The payoffs in the lotteries remain constant but the probability associated with each payoff changes. Lottery A is associated with a higher expected pay-off in the first few choices but this switches to lottery B in the later choices.

The MPL was adapted by presenting the lotteries as different healthcare treatments with payoffs defined as days of full health (Table 1). A risk-neutral individual should switch from the 'safe'

\footnotetext{
1 Round 1 of data collection started in September 2010, lasted 5 weeks and included 91 patients. Round 2 started in January 2011, lasted 4 weeks and included 34 patients. Round 3 started in April 2011, lasted 5 weeks and included 56 patients. Round 4 started in October 2011, lasted 4 weeks and included 119 patients. It should be noted that the survey was conducted at a time of great economic crisis. The potential implications are discussed in detail in Galizzi et al. (2016).
} 
Table 1

Adaptation of the Holt and Laury (2002) MPL test to measure risk preferences in the healthcare domain.

\begin{tabular}{|c|c|c|c|c|c|c|c|c|c|c|}
\hline \multirow[t]{2}{*}{ ID } & \multicolumn{4}{|c|}{ Treatment A } & \multicolumn{4}{|c|}{ Treatment B } & \multicolumn{2}{|c|}{ Your Choice } \\
\hline & $\mathrm{P}$ & Days in full health & $\mathrm{P}$ & Days in full health & $\mathrm{P}$ & Days in full health & $\mathrm{P}$ & Days in full health & A & B \\
\hline 1 & $10 \%$ & 200 & $90 \%$ & 160 & $10 \%$ & 385 & $90 \%$ & 10 & A & B \\
\hline 2 & $20 \%$ & 200 & $80 \%$ & 160 & $20 \%$ & 385 & $80 \%$ & 10 & A & B \\
\hline 3 & $30 \%$ & 200 & $70 \%$ & 160 & $30 \%$ & 385 & $70 \%$ & 10 & A & B \\
\hline 4 & $40 \%$ & 200 & $60 \%$ & 160 & $40 \%$ & 385 & $60 \%$ & 10 & A & B \\
\hline 5 & $50 \%$ & 200 & $50 \%$ & 160 & $50 \%$ & 385 & $50 \%$ & 10 & A & B \\
\hline 6 & $60 \%$ & 200 & $40 \%$ & 160 & $60 \%$ & 385 & $40 \%$ & 10 & A & B \\
\hline 7 & $70 \%$ & 200 & $30 \%$ & 160 & $70 \%$ & 385 & $30 \%$ & 10 & A & B \\
\hline 8 & $80 \%$ & 200 & $20 \%$ & 160 & $80 \%$ & 385 & $20 \%$ & 10 & A & B \\
\hline 9 & $90 \%$ & 200 & $10 \%$ & 160 & $90 \%$ & 385 & $10 \%$ & 10 & A & B \\
\hline
\end{tabular}

option (treatment A) to the 'risky' option (treatment B) only when the expected utility is greater in treatment $B$ than in A. An individual who is risk neutral chooses treatment $A$ in rows $1-4$, before switching to $B$ in row 5 . A risk averse individual switches to treatment $B$ after row 5 , whilst a risk lover switches before row 5 . Thus, the switching point is a measure of an individual's risk preferences. We define SwitchRiskHP (SwitchRiskHD) a variable denoting the point at which a given patient (doctor) switched from lottery A to lottery $B$. This ranges from 1 (switching to treatment $B$ in the first row) to 10 (never switching to treatment B) and the higher the value, the more risk averse the patient (doctor) is.

\subsubsection{Time preferences}

Time preferences were measured using an adaptation of the Tanaka et al. (2010) MPL to the healthcare context. Subjects were presented with a series of six blocks of choices, each of which had five choices between two different healthcare treatments. Subjects were asked to consider their current health status and to choose between two possible hypothetical treatments, A and B, with different days of full health at different points in time (Table 2 ). In each block, treatment A gave a larger number of days in full health than treatment B. Treatment A, however, was offered with some delay (so-called Larger-Later option, LL) whilst treatment B was always available immediately (so-called Smaller-Sooner option, SS). Treatment B offered progressively a larger number of days in full health. The time delay varied between blocks of lotteries from 1 week (blocks 1 and 4) to 1 month (blocks 2 and 5), to 3 months (blocks 3 and 6 ). We used switching points as simple measures of individual time preferences. The later individuals switch from treatment A to treatment $B$ the more patient they are. The variable SwitchTimeHPBi (SwitchTimeHDBi) denotes the specific point at which a given patient (doctor) switched from option $A$ to option $B$ in the block of questions $i$. The values range from 1 to 6 and the higher the value, the more patient the subject is.

\subsection{Analysis}

We examine differences in risk and time preferences between patients and doctors using two measures for individual preferences. First, we examine switching points in the MPL tests as indicators of individual risk and time preferences. The higher the value of the SwitchRiskHP (SwitchRiskHD) variable, the more risk

Table 2

Adaptation of the Tanaka et al. (2010) test to measure time preferences in the healthcare domain.

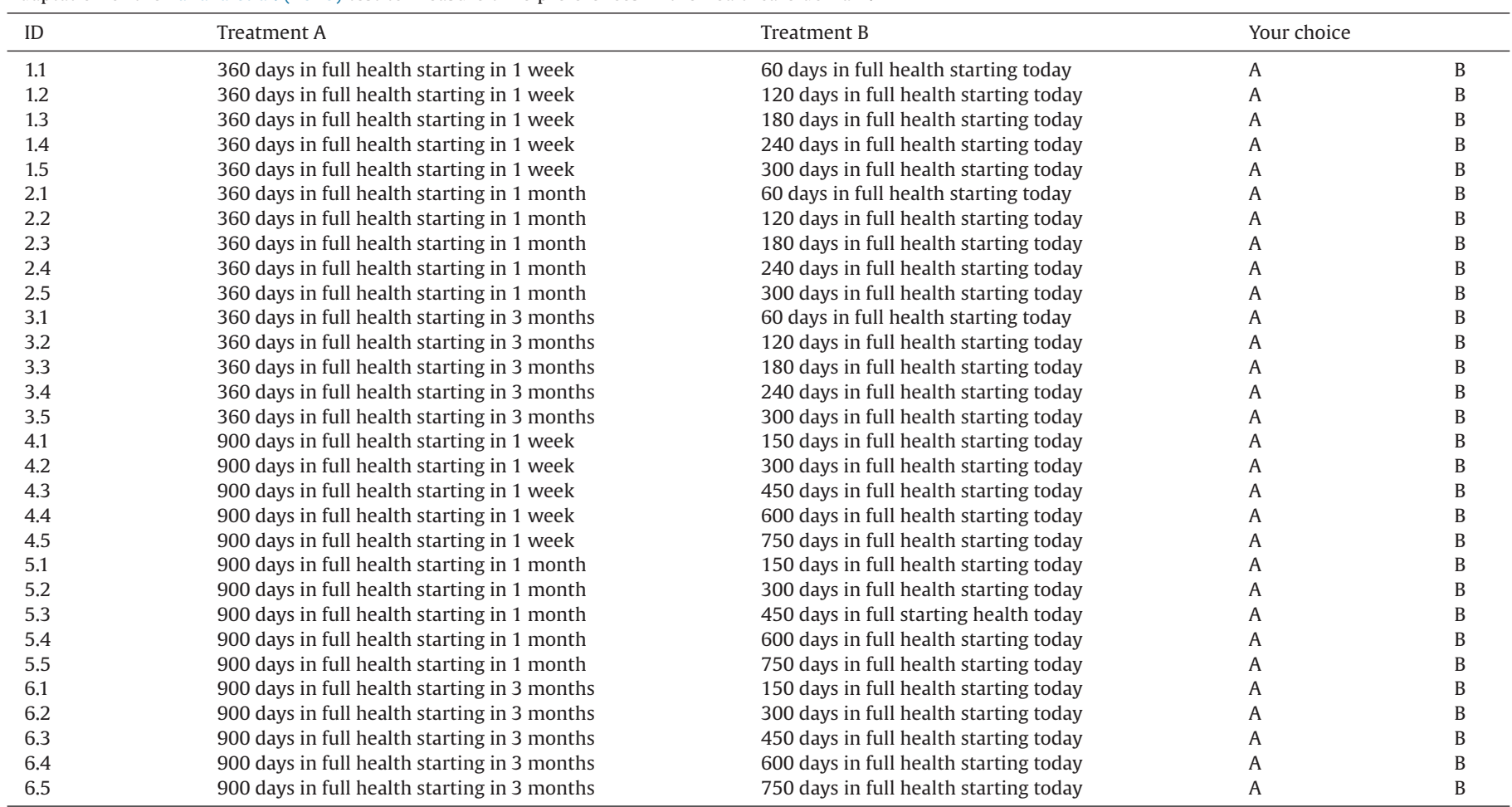


averse in healthcare a patient (doctor) is. Similarly, the higher the value of the SwitchTimeHPBi (SwitchTimeHDBi) variable the more patient in healthcare a patient (doctor) is. The Shapiro-Wilk test for normality rejects the null hypothesis that the switching points are normally distributed and we therefore test for differences in means between patients and doctors using the non-parametric (Wilcoxon) Mann-Whitney test. Even though doctors and patients may on average differ in their time and risk preferences, it could be the case that there is no difference in preferences in matched doctor-patient pairs and vice versa. It is therefore important to examine the difference in matched pairs as well as the difference in overall mean between doctors and patients. This is done by examining the number of patients who have identical or similar switching points to their doctors. We test for differences in switching points in matched pairs using the Wilcoxon matched-pairs signed-ranks test. As mentioned previously, $48 \%$ of patients can be matched to their doctor. Statistical tests (chi-square and t-tests) show that this sub-sample is similar to the whole sample in terms of sociodemographic characteristics.

Second, we 'structurally' estimate the behavioural parameters within the utility functions. We separately estimate risk and time preferences following the empirical approaches by Harrison and Rutström (2008a), Andersen et al. (2010), and Tanaka et al. (2010). We assume that the health-related risk preferences can be represented by a constant relative risk aversion (CRRA) utility function. The utility function of a subject in terms of healthcare payoffs $x$, is thus represented by

$U(x)=\frac{x^{1-s}}{1-s}$

where $s$ is the coefficient of constant relative risk aversion in the healthcare context. Depending on the value of $s$ a subject shows different degrees of risk aversion in the healthcare domain that can be grouped in three main types:

1. if $s=0$ risk neutral

2. if $s>0$ risk averse

3. if $s<0$ risk seeking

Maximum Likelihood (ML) methods were used to empirically estimate risk preferences (Harrison and Rutström, 2008a and Andersen et al., 2010). From Equation (1) $U(x)$ is the utility that a subject perceives from getting a healthcare benefit $x$. Under Expected Utility Theory, the expected utility by a subject of a given lottery $j=A, B$ is the utility of each outcome $k=1,2$ in that lottery, weighted by the probability $p_{k}$ of the outcome:

$E U_{j}=\sum_{k=1,2} p_{k j} * U\left(x_{k j}\right)$

with $j=A, B$ and $k=1,2$. The expected utility depends on the subject's risk aversion parameter $s$. Based on a candidate value of $s$ a latent preference index $\Delta(E U)$ can be constructed. Our empirical model allows subjects in the outpatient clinics to make stochastic errors when comparing expected utilities. We include in our estimation a parameter $\mu$ to capture the stochastic error, so that the latent index is:

$$
\Delta(E U)=\frac{\left(E U_{A}\right)^{1 / \mu}}{\left(E U_{A}\right)^{1 / \mu}+\left(E U_{B}\right)^{1 / \mu}}
$$

When $\mu \rightarrow 0$ the stochastic errors become negligible and the empirical specification reduces to a deterministic EUT choice, where the subject always chooses the lottery with higher perceived expected utility. When, however, $\mu$ gets larger, $\mu \rightarrow \pm \infty$, the choice between the two lotteries becomes essentially random, with the value of the latent index function approaching $1 / 2$ for any values of the expected utilities. We assume that the latent index $\Delta(E U)$ follows a logistic cumulative density function (CDF) taking values between 0 and 1 , so that $\Lambda(\Delta(E U))$ can be thought to link the latent preferences and the binary choices observed in the experiment (1):

$\operatorname{Prob}($ choosing lottery $A)=\Lambda(\Delta(E U))$

Under the assumptions of Expected Utility Theory and of CRRA utility functions, the likelihood of observing a specific choice depends on the individual risk preference $s$, given the logistic $C D F$ linking the latent index to the observed choices. The individual loglikelihood of choosing either lottery in each of the observed choices $C_{i}$, in our experiment is given by:

$\operatorname{LnL}(s, \mu ; C)=\sum_{i}\left(\left(\ln \Lambda(\Delta(E U)) \mid C_{i}=1\right)+\left(\left(\ln \Lambda(1-\Delta(E U)) \mid C_{i}=0\right)\right.\right.$

where $C_{i}=1(0)$ denotes the choice of lottery $A(B)$ in the proposed pair of lotteries $i$. The ML was adjusted to allow the CRRA parameter $s$ to be a linear function $s=s_{0}+s_{1} D$ where $D$ is a dummy variable taking value 1 for doctors and 0 for patients.

For time preferences we follow the procedure by Tanaka et al. (2010) to estimate the shape of the discounting function for patients and doctors. Tanaka et al. (2010) use a general discounting model originally proposed by Benhabib et al. (2010) which allows to test exponential, hyperbolic, and quasi-hyperbolic discounting as 'nested' cases of a more general discounting function. The discounting model assigns to a healthcare benefit $y$ at time $t>0$ a value of

$y \beta(1-(1-\theta) r t)^{1 /(1-\theta)}$

(and a value $y$ for immediate healthcare benefit at $t=0$ ). The three factors $r, \beta$, and $\theta$ identify the levels of baseline time discounting $(r)$, present bias $(\beta)$, and hyperbolicity of the discounting function $(\theta)$, respectively.

This general discounting model nests the three most common discounting specifications as special cases. In particular, when $\beta=1$ as $\theta \rightarrow 1$ the discounted value reduces to the conventional exponential discounting model in the limit, $e^{-r t}$ (Samuelson, 1947). When $\beta=1$ as $\theta=2$ the discounted value reduced to the 'pure hyperbolic' discounting model, $\left(\frac{1}{1+r t}\right)$ (Loewenstein and Prelec, 1992). ${ }^{2}$ When, finally, $\theta \rightarrow 1$ and $\beta$ is a free parameter, then the discounted value reduces to the 'quasi-hyperbolic' or 'present bias' discounting model $\beta e^{-r t}$ (Laibson, 1997; Phelps and Pollak, 1968).

We denote the probability of choosing immediate reward of $x$ over the delayed reward of $y$ in $t$ days by $P(x>(y, t))$ and use a logistic function to describe this relationship (7):

$P(x>(y, t))=\frac{1}{1+\exp \left(-\mu\left(x-y \beta(1-(1-\theta) r t)^{1 / 1-\theta}\right)\right)}$

where $r, \beta, \theta$ are the above defined parameters, and $\mu$ is a response sensitivity or 'noise' parameter.

\footnotetext{
2 The 'hyperbolic' model originally proposed by Loewenstein and Prelec (1992) actually takes the more general form where the parameter $h$ can be interpreted as a measure of 'decreasing impatience' (Attema et al., 2010; Bleichrodt et al., 2014; Prelec, 2004; Rohde, 2010). When $h=0$, the hyperbolic discounting is equivalent to exponential discounting. The higher the $h$, the more individual discounting deviates from constant discounting. The Loewenstein and Prelec (1992) general hyperbolic model nests further specific models such as the 'power' discounting model when $h=1$ (Harvey, 1986, 1995), and the 'proportional' discounting model when $h=r$ (Mazur, 1987), which is the 'pure hyperbolic' specification fitted in our estimations.
} 
A dummy variable for doctors is included in the models to examine whether parameters vary across doctors and patients. For example, for the 'present bias' model, we fit a logistic function (8)

$P(x>(y, t))=\frac{1}{1+\exp \left(-\mu\left(x-y \beta e^{-r t}\right)\right)}$

where $\beta=\beta_{0}+\beta_{1} D, r=r_{0}+r_{1} D$, and $D$ is a dummy variable taking value 1 for doctors and 0 for patients.

All estimates were obtained using an iterative nonlinear least square regression procedure with standard errors clustered at individual level, and a minimum number of 100 iterations at 99 percent significance level. When initial values had to be specified in order to help convergence of estimations, multiple replications were performed using a range of different initial values.

\subsubsection{Robustness checks and further analysis}

Both the time and risk preference tasks were conducted from the perspective of the subject's current health status. This raises two issues. First, the size of the health gain from the treatment varies across subjects depending on the level of their current health. The health gain is likely to be larger on average for patients compared to their doctors. Earlier empirical evidence suggests that individuals tend to be more risk averse for larger gains although this is now being debated (Harrison et al., 2005b; Holt and Laury, 2002, 2005). If true, this may bias the results towards patients being more risk averse. The time preference literature suggests that individuals discount larger gains at a lower rate than smaller gains (Andersen et al., 2013; Benzion et al., 1989; Chapman and Elstein, 1995; Green et al., 1997; Kirby and Maraković, 1996; Scholten and Read, 2010; Thaler, 1981). This may bias the results towards patients being more patient. To explore this we examine whether switching points are a function of self-assessed health using both a chi-square test and a Pearson correlation coefficient. The estimated difference between doctors and patients is less likely to be biased by differences in health gains if there is no statistically significant relationship between selfassessed health and switching point. If there is a significant relationship the sign of the correlation will indicate the direction in which the results may be biased.
Secondly, the use of current health state raises the issue of satiation in subjects who are in full health. Individuals may express indifference (zero time preference and risk neutrality) in that case or not engage with the tasks. We explore this by replicating the analysis excluding subjects who reported to be in full health.

To further test the robustness of our results, we also compare time and risk preferences between patients and doctors in the finance domain using the Tanaka et al. (2010) MPL test and the Holt and Laury (2002) MPL test (Online Appendix A2). In the financial domain, the size of the gain is the same across all subjects and none of the subjects will be satiated. Whilst time and risk preferences have been shown to be domain specific (Attema, 2012; Barseghyan et al., 2011; Blais and Weber, 2006; Bleichrodt and Johannesson, 2001; Bleichrodt et al., 1997; Butler et al., 2012; Cairns, 1994; Chapman, 1996; Chapman and Elstein, 1995; Cubitt and Read, 2007; Einav et al., 2010; Finucane et al., 2000; Galizzi et al., 2016; Hanoch et al., 2006; Hardisty and Weber, 2009; Hershey and Schoemaker, 1980; Jackson et al., 1972; MacCrimmon and Wehrung, 1990; Prosser and Wittenberg, 2007; Viscusi and Evans, 1990; Weber et al., 2002), it could be argued that, if the domain effect is similar across patients and doctors, then the difference in preferences between doctors and patients should be similar across domains. Similar differences across the two domains would increase the confidence we can place on the healthcare results.

\section{Results}

\subsection{Summary statistics}

The summary statistics for the two samples of patients and doctors are reported in Table 3. Due to missing values the sample size for estimating time and risk preferences varies from 241 to 294 for patients and from 56 to 66 for doctors. The four patients who switched back in the time preference tasks were omitted from the analysis.

The statistics show that, with the exceptions of income (and education) levels, age, and self-assessed health, doctors and patients in our sample have comparable socio-demographic characteristics.

Table 3

Descriptive statistics.

\begin{tabular}{|c|c|c|c|c|c|c|c|c|c|c|}
\hline \multirow[t]{2}{*}{ Variable } & $\mathrm{N}$ & Mean & Std. Dev. & Min & Max & $\mathrm{N}$ & Mean & Std. Dev. & Min & Max \\
\hline & \multicolumn{5}{|c|}{ Patients } & \multicolumn{5}{|c|}{ Doctors } \\
\hline SwitchHRisk & 281 & 5.06 & 2.57 & 0 & 10 & 58 & 5.03 & 2.05 & 1 & 10 \\
\hline SwitchHTimeB1 & 273 & 4.39 & 1.93 & 1 & 6 & 63 & 4.88 & 1.69 & 1 & 6 \\
\hline SwitchHTimeB2 & 265 & 3.35 & 2.03 & 1 & 6 & 60 & 4.2 & 1.93 & 1 & 6 \\
\hline SwitchHTimeB3 & 252 & 2.68 & 2.02 & 1 & 6 & 61 & 3.52 & 1.98 & 1 & 6 \\
\hline SwitchHTimeB4 & 248 & 4.63 & 1.89 & 1 & 6 & 60 & 4.8 & 1.91 & 1 & 6 \\
\hline SwitchHTimeB5 & 242 & 3.41 & 2.01 & 1 & 6 & 56 & 4.12 & 2.15 & 1 & 6 \\
\hline SwitchHTimeB6 & 241 & 2.81 & 2.03 & 1 & 6 & 56 & 3.8 & 2.14 & 1 & 6 \\
\hline SwitchFRisk & 294 & 4.90 & 2.75 & 1 & 10 & 59 & 5.52 & 2.36 & 1 & 10 \\
\hline SwitchFTimeB1 & 294 & 4.12 & 1.98 & 1 & 6 & 66 & 4.77 & 1.65 & 1 & 6 \\
\hline SwitchFTimeB2 & 293 & 3.05 & 1.88 & 1 & 6 & 65 & 4.36 & 1.62 & 1 & 6 \\
\hline SwitchFTimeB3 & 292 & 2.43 & 1.77 & 1 & 6 & 66 & 3.64 & 1.77 & 1 & 6 \\
\hline SwitchFTimeB4 & 291 & 4.67 & 1.87 & 1 & 6 & 65 & 5.14 & 1.39 & 1 & 6 \\
\hline SwitchFTimeB5 & 290 & 3.71 & 1.97 & 1 & 6 & 66 & 4.44 & 1.63 & 1 & 6 \\
\hline SwitchFTimeB6 & 289 & 2.69 & 1.83 & 1 & 6 & 66 & 3.57 & 1.81 & 1 & 6 \\
\hline Age & 238 & 39.61 & 12.93 & 18 & 74 & 61 & 36.59 & 8 & 27 & 63 \\
\hline Female & 300 & 0.48 & 0.50 & 0 & 1 & 67 & 0.46 & 0.50 & 0 & 1 \\
\hline Educ & 238 & 5.59 & 1.63 & 2 & 8 & & & & & \\
\hline Married & 300 & 0.34 & 0.47 & 0 & 1 & 67 & 0.38 & 0.49 & 0 & 1 \\
\hline Children & 300 & 0.34 & 0.47 & 0 & 1 & 67 & 0.23 & 0.43 & 0 & 1 \\
\hline FinConstr & 232 & 2.45 & 0.74 & 1 & 4 & 60 & 2.03 & 0.66 & 1 & 3 \\
\hline $\mathrm{SAH}$ & 300 & 2.39 & 1.16 & 1 & 5 & 67 & 1.62 & 0.73 & 1 & 4 \\
\hline Chronic & 300 & 0.17 & 0.37 & 0 & 1 & & & & & \\
\hline
\end{tabular}


Table 4

Differences in time preferences between doctors and patients.

\begin{tabular}{|c|c|c|c|c|c|c|}
\hline & TimeB1 & TimeB2 & TimeB3 & TimeB4 & TimeB5 & TimeB6 \\
\hline \multicolumn{7}{|l|}{ Healthcare } \\
\hline Number of patients & 273 & 265 & 252 & 248 & 242 & 241 \\
\hline Number of doctors & 63 & 60 & 61 & 60 & 56 & 56 \\
\hline Switching point mean patients & 4.39 & 3.35 & 2.68 & 4.63 & 3.41 & 2.81 \\
\hline Switching point mean doctors & 4.88 & 4.2 & 3.52 & 4.8 & 4.1 & 3.80 \\
\hline z statistic & -1.911 & -2.770 & -2.940 & -0.899 & -2.249 & -2.937 \\
\hline p-value & 0.0560 & 0.0056 & 0.0033 & 0.3685 & 0.0245 & 0.0033 \\
\hline \multicolumn{7}{|l|}{ Finance } \\
\hline Number of patients & 294 & 293 & 292 & 291 & 290 & 289 \\
\hline Number of doctors & 66 & 65 & 66 & 65 & 66 & 66 \\
\hline Switching point mean patients & 4.12 & 3.06 & 2.43 & 4.67 & 3.71 & 2.69 \\
\hline Switching point mean doctors & 4.77 & 4.35 & 3.64 & 5.14 & 4.44 & 3.57 \\
\hline z statistic & -2.343 & -4.941 & -4.985 & -1.457 & -2.555 & -3.558 \\
\hline p-value & 0.0191 & 0.0000 & 0.0000 & 0.1451 & 0.0106 & 0.0004 \\
\hline
\end{tabular}

Note: P-values refer to tests of the null hypothesis that switching points are not statistically significantly different across patients and doctors.

\subsection{Switching points measures for risk and time preferences: differences between patients and doctors}

We start by examining differences in risk preferences. The mean switching point in the healthcare domain was SwitchHRiskP $=5.06$ $(\mathrm{SD}=2.57)$ for patients and SwitchHRiskD $=5.03(\mathrm{SD}=2.05)$ for doctors. The Mann-Whitney test failed to reject the null hypothesis that SwitchHRiskP $=$ SwitchHRiskD $(\mathrm{z}=-0.332, \mathrm{p}=0.7401)$, suggesting that health-related risk preferences are similar for doctors and patients.

The lack of significance of the chi-square test and the Pearson correlation ( $\mathrm{p}=0.433$ and $\mathrm{p}=0.0875$ respectively) suggest that there is no significant relationship between risk preferences and selfassessed health. The potential difference in the size of the health gain between doctors and patients is therefore unlikely to have biased the comparison. To further test the robustness of the results we also compare risk preferences in the financial domain. The mean switching point in the finance domain was SwitchFRiskP=4.90 ( $\mathrm{SD}=2.75)$ for patients, whilst for the doctors it was SwitchFRiskD $=5.52$ $(\mathrm{SD}=2.36)$. The Mann-Whitney rejects the null hypothesis that SwitchFRiskP $=$ SwitchFRiskD at a 95\% significance level $(\mathrm{z}=-1.973$, $\mathrm{p}=0.0485$ ), suggesting a significant difference in the financerelated risk preferences between the two groups, with the doctors being more risk averse in finance than patients.

In case of time preferences, a relatively large proportion of doctors and patients never switched from option A to option B, with the exact proportion varying per block of questions. In the healthcare domain the percentage of respondents never switching were $50 \%$ in the first block, $28 \%$ in the second, $19 \%$ in the third, $57 \%$ in the fourth block, $32 \%$ in the fifth and $25 \%$ in sixth block. Similar figures hold for the finance domain.

Table 4 shows that in healthcare the mean switching points for doctors are higher across all six blocks of pairwise choices, and the doctor-patient differences are significant in all cases but the fourth block. Note that the doctor-patient differences are only marginal- ly significant in the first block. This suggests that doctors are more patient when discounting future health outcomes than patients, at least for time delays longer than a week. The significance of the chisquare test and the Pearson correlation suggest that there is a significant relationship between time preferences and self-assessed health ( $p$-values for chi-square test range from 0.0001 to 0.1001 across the six blocks, and the p-values for the Pearson correlation range from 0.0000 to 0.0001 ). The correlation is negative suggesting that larger health gains (lower self-assessed health) are discounted at a higher rate. The difference in time preferences may therefore be caused by the difference in current health status between doctors and patients. To explore this further we also compare time preferences in the financial domain. Table 4 shows that the results for time preferences for money are very similar in that doctors are significantly more patient than their patients.

Table 5 shows the difference in switching points between matched doctor-patient pairs. The proportion of patients who have identical time and risk preferences to their doctor ranges from $19.5 \%$ for risk preferences to $38.9 \%$ for time preferences (fourth block). Switching points are 2 or more apart from their doctors for around $50 \%$ of patients. The results of the Wilcoxon matched pairs test are in line with the results for the aggregate preferences. There are no differences in risk preferences but matched doctor-patients do differ in terms of their time preferences. That the results are similar is perhaps not surprising given that patients in our outpatient clinics were randomly assigned to a doctor.

\subsection{Structural estimation of risk and time preferences: differences between patients and doctors}

Table 6 shows the ML results which allow the fitted parameters to be a function of a doctor dummy variable, in order to estimate differences across the two types of respondents. The estimates for the two subsamples of doctors and patients are reported in Appendix B and are in line with the pooled results. The table also

Table 5

Difference in switching point in matched doctor-patient pairs.

\begin{tabular}{|c|c|c|c|c|c|c|c|}
\hline & \multicolumn{2}{|c|}{ No difference } & \multicolumn{2}{|c|}{ Difference of 1 point } & \multicolumn{2}{|c|}{ Difference of more than 1 point } & \multirow{2}{*}{$\begin{array}{l}\text { Wilcoxon matched pairs test } \\
\text { p-value }\end{array}$} \\
\hline & $\mathrm{N}$ & $\%$ & $\mathrm{~N}$ & $\%$ & $\mathrm{~N}$ & $\%$ & \\
\hline SwitchHRisk & 24 & 19.5 & 31 & 25.2 & 68 & 55.3 & 0.1074 \\
\hline SwitchHTimeB1 & 43 & 33.6 & 17 & 13.3 & 68 & 53.1 & 0.0002 \\
\hline SwitchHTimeB2 & 32 & 27.4 & 21 & 17.9 & 64 & 54.7 & 0.0000 \\
\hline SwitchHTimeB3 & 38 & 35.2 & 14 & 13.0 & 56 & 51.9 & 0.0000 \\
\hline SwitchHTimeB4 & 42 & 38.9 & 8 & 7.4 & 58 & 53.7 & 0.0036 \\
\hline SwitchHTimeB5 & 34 & 34.3 & 13 & 13.1 & 52 & 52.5 & 0.0125 \\
\hline SwitchHTimeB6 & 34 & 35.4 & 12 & 12.5 & 50 & 52.1 & 0.0000 \\
\hline
\end{tabular}


Table 6

Estimated risk aversion parameters under CRRA.

\begin{tabular}{lcccc}
\hline \multicolumn{4}{c}{ Healthcare domain } & Finance domain \\
\hline $\mathrm{s}$ & $0.1415^{* * *}$ & $0.1211^{* *}$ & 0.0432 & -0.0135 \\
& $(0.0470)$ & $(0.0522)$ & $(0.0535)$ & $(0.0578)$ \\
$\mathrm{s}^{\mathrm{d}}$ & -0.0138 & 0.0872 & 0.0253 & $0.3352^{* * *}$ \\
& $(0.0322)$ & $(0.1092)$ & $(0.0315)$ & $(0.1173)$ \\
$\mu$ & $30.8911^{* * *}$ & $34.5442^{* * *}$ & $52.3180^{* * *}$ & $71.8444^{* * *}$ \\
& $(6.6939)$ & $(8.5517)$ & $(13.4195)$ & $(20.7522)$ \\
$\mu^{\mathrm{d}}$ & & -14.8975 & & $-59.5904^{* * *}$ \\
& & $(12.0268)$ & & $(21.5227)$ \\
Observations & 3051 & 3051 & 3177 & 3177 \\
Log pseudo LL & -1721.87 & -1719.70 & -1771.23 & -1756.73
\end{tabular}

Notes: ${ }^{*} \mathrm{p}<0.1,{ }^{* *} \mathrm{p}<0.05,{ }^{* * *} \mathrm{p}<0.01$. Sample size in the healthcare domain is 3051 : 9 observations for 281 patients and 58 doctors. Sample size in the financial domain is 3177: 9 observations for 294 patients and 59 doctors.

Superscript $d$ refers to the doctors' dummy variables.

shows that the doctor dummy variable is not statistically significant in the estimates for the CRRA parameter in the healthcare domain, confirming that there are no systematic differences in risk preferences for healthcare outcomes across doctors and patients. The doctor dummy variable is also not significant in the estimates for the stochastic error $\mu$, suggesting that doctors and patients are equally likely to make errors in their responses to the test. In the finance domain, the doctors' dummy variable is significantly associated with both the CRRA and the noise coefficient: doctors are more risk averse in finance than patients, and also make fewer errors in their choices compared to patients.

As for time preferences, due to the relatively small number of observations for the doctors, we were unable to reliably fit the general discounting model. We therefore focus on the estimation of the three 'nested' discounting models: (i) the 'exponential' model; (ii) the 'pure' hyperbolic discounting model; and (iii) the 'quasi-hyperbolic' or 'present bias' model. Table 7 shows the results for the three different discounting models. ${ }^{3}$ In the healthcare domain, the estimated coefficient for the doctor dummy variable is negative and highly significant in both the 'exponential' and the 'pure hyperbolic' model $(-0.015$, with $S E=0.0036$, and -0.0248 with $S E=0.0064$, respectively), suggesting that doctors are less impatient than patients. The estimated coefficient for the doctor dummy variable is also negative and highly significant in the finance domain $(-0.0135$, with $S E=0.0025$, in the 'exponential' model, and -0.0237 , with $S E=0.0047$, in the 'pure hyperbolic' model). In the 'present bias' model, the doctor dummy variable is negative and highly significant for the long-run discounting rates $(-0.0159$, with $S E=0.0034$, in the healthcare domain; and -0.0096 , with $S E=0.0020$, in the finance domain), but does not reach statistical significance for the present bias parameter $(0.0144$, with $S E=0.1126$, in the healthcare domain, and 0.1033 , with $S E=0.0813$, in the finance domain). Estimates also confirm that doctors are generally less impatient than patients, and that, the present bias parameter is not significantly different from one.

\footnotetext{
3 Sample size in Table 7 differs across the healthcare and the finance domains due to different missing data in the different blocks of time preferences questions. In the healthcare domain, 273 patients and 63 doctors answered the first block of questions; 265 patients and 60 doctors answered the second block of questions; 252 patients and 61 doctors answered the third block of questions; 248 patients and 60 doctors answered the fourth block of questions; 242 patients and 56 doctors answered the fifth block of questions; and 241 patients and 56 doctors answered the last block of questions. Since each block had five time preferences questions, this gives a total of 9385 responses in the healthcare domain. Similarly, in the financial domain, 294 patients and 66 doctors answered the first block of questions; 293 patients and 65 doctors answered the second block of questions; 292 patients and 66 doctors answered the third block of questions; 291 patients and 65 doctors answered the fourth block of questions; 290 patients and 66 doctors answered the fifth block of questions; and 289 patients and 66 doctors answered the last block of questions. This gives a total of 10,715 responses in the finance domain.
}

The goodness of fit of the estimated discounting models is relatively high with the adjusted $R^{2}$ ranging from 0.5243 to 0.5301 in the healthcare domain, and from 0.5690 to 0.5706 in the finance domain. The goodness of fit does not vary substantially across the different specifications within the same domain.

The above estimates of the risk and time preferences parameters and of the doctor-patient dummy are robust to the introduction in the models of further covariates, such as gender, age, financial state, and self-assessed health. Finally, similar results were found when excluding subjects who reported to be in full health suggesting that satiation might not have been an issue (results available upon request).

\section{Discussion}

Our data suggest that there is no systematic difference in risk preferences in the healthcare domain between doctors and patients: both doctors and patients tend to be mildly risk averse in the healthcare domain. It could be argued that the lack of significant doctor-patient differences in risk preferences in health is not due to a genuine similarity of the underlying risk preferences, but is partly an artefact of the differences in perceived health gains with doctors closer to being 'satiated' in health than patients. ${ }^{4}$ On average, doctors' self-reported health was higher than patients (1.62 compared to 2.39). However, we found no significant relationship between risk preferences and self-assessed health. This is in line with other studies which have questioned the earlier evidence that individuals tend to be more risk averse for larger (monetary) outcomes (Harrison et al., 2005b; Holt and Laury, 2002, 2005). If the earlier evidence holds, this would imply that doctors would be more risk averse if presented with larger health gains. Therefore, the nonsignificant small difference in risk aversion in healthcare between patients and doctors found in our estimations may have resulted from an underestimation of risk aversion in doctors.

The use of current health state as the reference point also raises the question as to how subjects in good health answered the questions as they were 'satiated' in their level of health. Around half of the doctors $(51.25 \%)$ reported to be in very good health. However, excluding subjects who reported to be in very good health did not change the results. Given that all subjects gave reasonable and meaningful answers all throughout the tests, and that the estimates of the CRRA coefficient are consistent with non-satiation (e.g. Harrison and Rutström, 2008b, p. 181), it may be the case that subjects who reported being in very good health used a reference health status worse than the self-reported health at the time they participated in the experiment. That is, subjects may have made sense of the scenario presented in a way more consistent with the life-time health losses they experienced or expected to experience. Therefore it is possible that their answers were implicitly anchored to a poorer health status than their reported self-assessed health.

We also compared risk preferences across doctors and patients in the financial domain as a further robustness check. In the financial domain, the size of the gain was the same across all subjects and none of the subjects were satiated. However, it should be noted

\footnotetext{
4 Note that we have opted for having the same framing across patients and doctors in order to not confound the findings with differences in the framing. An alternative experiment design could consist of presenting both doctors and patients with the same baseline hypothetical health status scenario. Given the non-observable differences in health status across patients, however, it would not be possible to elicit which health status (whether their own status or the hypothetical baseline status) was more salient in patients' choices. It is plausible to presume that the most salient would be the most severe health status, implying that a patient with a cancer diagnosis would anchor her choices to her real health status, whereas a doctor in full health would be more likely to anchor his choices to the hypothetical baseline scenario.
} 
Table 7

Estimated discounting parameters under exponential, hyperbolic, and quasi-hyperbolic discounting models.

\begin{tabular}{|c|c|c|c|c|c|c|}
\hline & \multicolumn{3}{|c|}{ Healthcare domain } & \multicolumn{3}{|l|}{ Finance domain } \\
\hline & Exponential & Hyperbolic & Quasi-hyperbolic & Exponential & Hyperbolic & Quasi-hyperbolic \\
\hline \multirow[t]{2}{*}{$\mu$} & $0.0037^{* * * *}$ & $0.0042^{* * *}$ & $0.0035^{* * *}$ & $0.0045^{* * * *}$ & $0.0051^{* * *}$ & $0.0048^{* * *}$ \\
\hline & $(0.0002)$ & $(0.0002)$ & $(0.0002)$ & $(0.0002)$ & $(0.0003)$ & $(0.0003)$ \\
\hline \multirow[t]{2}{*}{$\mathrm{r}$} & $0.0215^{* * *}$ & $0.0338^{* * * *}$ & $0.0231^{* * *}$ & $0.0208^{* * * *}$ & $0.0339^{* * *}$ & $0.0171^{* * *}$ \\
\hline & $(0.0029)$ & $(0.0055)$ & $(0.0031)$ & $(0.0021)$ & $(0.004)$ & $(0.0017)$ \\
\hline \multirow[t]{2}{*}{ b } & & & $1.0404^{* * * *}$ & & & $0.8997^{* * * *}$ \\
\hline & & & $(0.0611)$ & & & $(0.0813)$ \\
\hline \multirow[t]{2}{*}{$r^{d}$} & $-0.015^{* * *}$ & $-0.0248^{* *}$ & $-0.0159^{* * * *}$ & $-0.0135^{* * *}$ & $-0.0237^{* * *}$ & $-0.0096^{* * *}$ \\
\hline & $(0.0036)$ & $(0.0064)$ & $(0.0034)$ & $(0.0025)$ & $(0.0047)$ & $(0.0020)$ \\
\hline \multirow[t]{2}{*}{$b^{d}$} & & & 0.0144 & & & 0.1033 \\
\hline & & & $(0.1126)$ & & & $(0.0813)$ \\
\hline Observations & 9,385 & 9,385 & 9,385 & 10,715 & 10,715 & 10,715 \\
\hline Adj R-squared & 0.5300 & 0.5243 & 0.5301 & 0.5690 & 0.5706 & 0.5697 \\
\hline
\end{tabular}

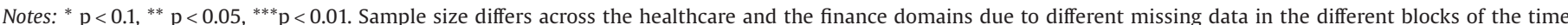
preferences questions. See footnote 4 for a detailed explanation.

Superscript $d$ refers to the doctors' dummy variables.

that doctors in our sample are generally on higher incomes than their patients, and income is known to be associated with risk preferences (Donkers et al., 2001). Doctors and patients did significantly differ in their risk preferences in the finance domain, with doctors being risk averse whilst patients are risk neutral. Moreover, the estimated CRRA coefficient for doctors in finance is higher than their CRRA coefficient in health (Appendix B), suggesting that the differences in risk preferences across doctors and patients may have been underestimated in the healthcare domain. An alternative explanation for the difference in risk preferences in the monetary domain is the difference in income levels.

In case of time preferences, our evidence suggests that doctors are more patient than their patients when deciding over healthcare treatments with benefits at different points in time. We do not find any support for present bias either in patients' or in doctors' time preferences for healthcare treatments. The above results are confirmed for the financial domain. We found a significant relationship between time preferences and self-assessed health with larger health gains being discounted at a higher rate. The difference in time preferences between doctors and patients may have therefore in part been caused by differences in the size of the health gain. However, we found a similar difference in time preferences between doctors and patients across the two domains.

For the health domain, the lack of present bias is in line with other recent studies which, using different methods, also reject the quasi-hyperbolic model for time preferences in health (Bleichrodt et al., 2014), but it is in contrast with earlier evidence on quasihyperbolic discounting for health outcomes (Cairns and Van der Pol, 1997; van der Pol and Cairns, 2002). For the finance domain, our findings may seem unexpected given the widespread support in favour of quasi-hyperbolic discounting among behavioural economists (Ainslie, 1975; Angeletos et al., 2001; DellaVigna and Malmendier, 2006; Diamond and Köszegi, 2003; Gruber and Köszegi, 2001, 2004; Kirby and Maraković, 1995; Kirby et al., 1999; Laibson, 1997; Loewenstein and Prelec, 1992; McClure et al., 2004; O'Donoghue and Rabin, 1999; Phelps and Pollak, 1968; Strotz, 1955; Thaler, 1981).

A number of reasons can explain the differences in findings, including the hypothetical rewards, the elicitation method, the subject pool, and the study setting. More generally, some recent experimental results on time preferences over monetary outcomes suggest that the evidence on hyperbolic discounting is not unanimous. For instance, a number of recent studies have failed to support the hypothesis of non-constant discounting, including Andreoni and Sprenger (2012), Laury et al. (2012), and Andersen et al. (2014). Furthermore, a review of the literature by Andersen et al. (2014) notices that all evidence to date on non-constant discounting with mone- tary outcomes refers either to hypothetical surveys, or to studies with no incentive-compatible rewards, or to lab experiments with student subjects. None of the studies included in the review by Andersen et al. (2014) elicits hypothetical health- and finance-related time preferences from doctors and patients in real clinical settings.

Our study adds to this evidence and, to the best of our knowledge, is the first study to suggest that patients and doctors in real clinical settings may not exhibit any significant present bias when making decisions on healthcare treatments over time. Given that quasi-hyperbolic discounting is associated to dynamic inconsistency, it is somehow reassuring to learn that, at least when it comes to healthcare decisions in real clinical settings, not only doctors but also patients exhibit time-consistent preferences. Similarly reassuring is the finding that there is no systematic difference in risk preferences between doctors and patients whey they make decisions over risky healthcare treatments. However, further evidence is needed to understand whether this is due to the specific healthcare domain, the clinical setting, the hypothetical nature of the decisions, or any other specific characteristics of our field study.

\section{Conclusions}

Preferences for risk and time are fundamental individual characteristics that have been found to be associated with numerous health and healthcare behaviours, including: heavy drinking (Anderson and Mellor, 2008; Bradford et al., 2014; Szrek et al., 2012), drink and driving (Sloan et al., 2014) smoking (Barsky et al., 1995; Bradford et al., 2014; Bradford, 2010; Burks et al., 2012; Dohmen et al., 2011; Goto et al., 2009), BMI (Borghans and Golsteyn, 2006; Chabris et al., 2008; Ikeda et al., 2010; Sutter et al., 2013; Weller et al., 2008), poor nutritional quality (Galizzi and Miraldo, 2012); as well as overall self-assessed health (Van Der Pol, 2011), the uptake of vaccinations, preventive care, and medical tests (Axon et al., 2009; Bradford, 2010; Bradford et al., 2010; Chapman and Coups, 1999; Picone et al., 2004) and adherence to treatments (Brandt and Dickinson, 2013; Chapman et al., 2001).

Surprisingly little attention has been paid to differences and similarities of risk and time preferences between doctors and their patients. These differences can potentially have a major impact on doctor-patient communication, healthcare decision-making, and treatment adherence. To the best of our knowledge, ours is the first field experiment to examine differences in risk and time preferences between doctors and patients in real clinical settings.

We have three main findings. First, there is a significant difference in time preferences across patients and their matched doctors, with doctors discounting future less heavily than patients. Second, we find no systematic difference in risk preferences in the health- 
care context between patients and doctors: in our sample both patients and their matched doctors are mildly, but significantly, risk averse in the healthcare domain. Third, patients and doctors have significantly different risk preferences in the finance domain: whilst doctors are risk averse, patients are risk neutral. This raises the question whether the healthcare results were biased due to differences in the size of health gain. However, no relationship was found between risk preferences and self-assessed health.

The findings have potential implications for health policy. In several healthcare contexts individuals are matched to their doctors and healthcare on characteristics such as gender and ethnicity (Cooper et al., 2003; Cooper-Patrick et al., 1999; Saha et al., 1999). A number of other interventions have been suggested to improve risk communication during the consultation with the aim of achieving better outcomes (Edwards et al., 2008; Fagerlin et al., 2011). Our research contributes to this line of research suggesting that the doctor-patient matching and communication could be more systematically informed by a broader set of characteristics, such as individual preferences for risk and time. As agents to their patients, doctors, for instance, should attempt to find out more about their patients' risk and time preferences when recommending specific healthcare treatments. Time and risk preferences are difficult to observe but are known to be associated with a number of more observable characteristics such as age, gender and income. One approach is therefore for the doctor to use these observable proxies of time and risk preferences to adjust their treatment recommendations. Given the availability of short questions on self-reported time and risk attitudes, it may also be possible for the doctor to obtain proxy indicators of their patients' preferences (Dohmen et al., 2011; Vischer et al., 2013). Perhaps a more realistic scenario is to make doctors aware of potential differences in time and risk preferences between themselves and their patients and to recommend that they explicitly discuss the relative weights that patients place on the timing and the risk of treatments. Shared decision making between doctors and patients has been found to associate with better health outcomes (Greenfield et al., 1985).

Our findings on time preferences suggest that doctors, aware that patients are discounting the future more heavily, should recommend treatments which reflect the higher weight placed on shorter term benefits. However, it has also been suggested that individuals may consider their heavy discounting of the future to be undesirable, and that they may wish to overcome their impatience (Becker and Mulligan, 1997). If this is the case, then this raises the question whether there is a role for the agent (doctor) to help the patients overcome their impatience for receiving the benefits from treatment.

The study is, of course, not without limitations. The experiments were conducted from the perspective of the participants' current health status. Future research should explore whether results are sensitive to the differences in the size of health gain across doctors and patients. Due to the ethics constraints related to approaching patients in hospital clinics, we were unable to conduct experimental tests with real, incentive-compatible rewards in order to measure risk and time preferences in the healthcare domain. It is widely known that individual responses may change when real rewards are at stake (Andersen et al., 2014; Blackburn et al., 1994; Cummings et al., 1995, 1997). In particular, in the finance domain, hypothetical tests are known to elicit less risk averse preferences than incentive-compatible tests (Battalio et al., 1990; Holt and Laury, 2002). The design and implementation of incentive-compatible tests to measure risk and time preferences in the health domain is a challenging but promising area where more work is needed.

Another aspect which deserves explicit investigation is looking at the interaction between risk and time preferences in health. For monetary outcomes, risk and time preferences have been found to closely correlate and interlink (Ahlbrecht and Weber, 1997, 1997;
Anderhub et al., 2001; Andersen et al., 2008b; Andreoni and Sprenger, 2012; Chesson and Viscusi, 2000; Coble and Lusk, 2010; Epstein and Zin, 1989a, 1989b; Frederick et al., 2002; Kreps and Porteus, 1978, 1978; Laury et al., 2012; Noussair and Wu, 2006; Onay and Öncüler, 2007; Stevenson, 1992, 1992; Weber and Chapman, 2005). The experimental economics literature has in fact developed 'structural estimation' models that jointly estimate risk and time preferences (Andersen et al., 2008b, 2014). A similar avenue is beyond the scope of the present study, but it can be usefully explored by the next generation of incentive-compatible tests for preferences in health.

Furthermore, in our experiment doctors completed a questionnaire, which asked them about their own risk and time preferences, just like patients did. This is consistent with the fact that doctors' own risk and time preferences have been shown to correlate with treatment decisions (Allison et al., 1998; Fiscella et al., 2000; Franks et al., 2000; Holtgrave et al., 1991). Doctors, moreover, may have different risk and time preferences regarding their own health from when they prescribe risky healthcare treatments to their patients (Atanasov et al., 2013; Beisswanger et al., 2003; Garcia-Retamero and Galesic, 2012, 2014). This is an intriguing question, and similar patterns have in fact been documented in other doctor-patient interaction contexts, such as the choice of healthcare treatments in a consultation (Ubel et al., 2011). The question, however, is beyond the direct scope of the present study, and is left for further research.

\section{Acknowledgements}

Financial support for this study was provided entirely by a Pumppriming grant from the Faculty of Business, Economics and Law at the University of Surrey. We gratefully acknowledge this funding from the University of Surrey. The funding agreement ensured the authors' independence in designing the study, interpreting the data, writing, and publishing the report. We thank Nigel Rice, three anonymous referees, and all participants of the Health Economics Research Unit seminar in Aberdeen (October 2013); the Health Economics Study Group workshop in Warwick (June 2013); and the Health Economics Research Centre seminar in Oxford (July 2013) for useful comments and suggestions. We are grateful to Aikaterini Anestaki, Omiros Stavropoulos and Theodoros Thomaidis for assistance with the data collection.

\section{Appendix A}

Description of variables

\begin{tabular}{|c|c|}
\hline Variable & Variable description \\
\hline \multicolumn{2}{|c|}{ Explanatory variables } \\
\hline \multicolumn{2}{|c|}{ Individual characteristics for patients and doctors } \\
\hline Age & Age in years \\
\hline Female & Female gender $(0=$ no, $1=$ yes $)$ \\
\hline Educ* & $\begin{array}{l}\text { Level of education }(1=\text { primary school....8 = doctoral or } \\
\text { post-graduate specialisation degree })\end{array}$ \\
\hline FinConstr & $\begin{array}{l}\text { Constrained by my financial state }(1=\text { living } \\
\text { comfortably...4 = find it very difficult })\end{array}$ \\
\hline Married & Married $(0=$ no, $1=$ yes $)$ \\
\hline Children & Having children $(0=$ no, $1=$ yes $)$ \\
\hline SAH & Self-assessed health $(1=$ very good $\ldots . .5=$ very bad $)$ \\
\hline Chronic* & Presence of a chronic condition $(0=$ no, $1=$ yes $)$ \\
\hline \multicolumn{2}{|l|}{ Risk variables } \\
\hline SwitchRiskHP & $\begin{array}{l}\text { Patients' risk aversion in healthcare implied by switching } \\
\text { point in the test ( } 1 \text { = extremely risk } \\
\text { seeking...10 = extremely risk averse })\end{array}$ \\
\hline SwitchRiskHD & $\begin{array}{l}\text { Doctors' risk aversion in healthcare implied by switching } \\
\text { point in the test }(1=\text { extremely risk } \\
\text { seeking... } 10=\text { extremely risk averse })\end{array}$ \\
\hline SwitchRiskFP & $\begin{array}{l}\text { Patients' risk aversion in finance implied by switching } \\
\text { point in the test ( } 1 \text { = extremely risk } \\
\text { seeking...10 = extremely risk averse })\end{array}$ \\
\hline
\end{tabular}

(continued on next page) 
Appendix A (continued)

\begin{tabular}{|c|c|}
\hline Variable & Variable description \\
\hline SwitchRiskFD & $\begin{array}{l}\text { Doctors' risk aversion in finance implied by switching } \\
\text { point in the test }(1=\text { extremely risk } \\
\text { seeking...10 = extremely risk averse) }\end{array}$ \\
\hline \multicolumn{2}{|r|}{ seeking... iv = extremery nisk dverse) } \\
\hline SwitchTimeHPBi & $\begin{array}{l}\text { Patients' time preference in healthcare implied by } \\
\text { switching point in block } i=1 \ldots 6(1=\text { least } \\
\text { patient...6 } 6 \text { most patient })\end{array}$ \\
\hline SwitchTimeHDBi & $\begin{array}{l}\text { Doctors' time preference in healthcare implied by } \\
\text { switching point in block } i=1 \ldots 6(1=\text { least } \\
\text { patient...6 } 6 \text { most patient })\end{array}$ \\
\hline SwitchTimeFPBi & $\begin{array}{l}\text { Patients' time preference in finance implied by switching } \\
\text { point in block } i=1 \ldots 6 \\
\text { ( } 1=\text { least patient...6 } 6 \text { most patient })\end{array}$ \\
\hline SwitchTimeFDBi & $\begin{array}{l}\text { Doctors' time preference in finance implied by switching } \\
\text { point in block } i=1 \ldots 6 \\
(1=\text { least patient...6 = most patient) }\end{array}$ \\
\hline
\end{tabular}

* Information obtained only for patients. In order to be consultants in outpatient clinics, all doctors must have at least one post-graduate medical specialisation.

\section{Appendix B}

Structural estimations for the two subsamples of doctors and patients

Table B1 Estimated risk aversion parameters in healthcare under CRRA for patients and doctors.

\begin{tabular}{|c|c|c|c|c|}
\hline & \multicolumn{2}{|c|}{ Healthcare domain } & \multicolumn{2}{|c|}{ Financial domain } \\
\hline & Patients & Doctors & Patients & Doctors \\
\hline \multirow[t]{2}{*}{ s } & $0.1211^{* *}$ & $0.2084^{* *}$ & -0.0135 & $0.3217^{* * *}$ \\
\hline & $(0.0523)$ & $(0.0966)$ & $(0.0578)$ & $(0.1027)$ \\
\hline \multirow[t]{2}{*}{$\mu$} & $34.5443^{* * *}$ & $19.6467^{* * *}$ & $71.8446^{* * * *}$ & $12.2540^{* *}$ \\
\hline & (8.5544) & (8.5086) & (20.7588) & (5.7425) \\
\hline Observations & 2700 & 603 & 2700 & 603 \\
\hline Log pseudo LL & -1422.77 & -296.93 & -1450.75 & -305.97 \\
\hline
\end{tabular}

Table B2 Estimated discounting parameters in the healthcare domain under exponential, hyperbolic, and quasi-hyperbolic discounting models.

\begin{tabular}{|c|c|c|c|c|c|c|}
\hline & \multicolumn{3}{|c|}{ Healthcare domain } & \multicolumn{3}{|c|}{ Financial domain } \\
\hline & Exponential & Hyperbolic & Quasi-hyperbolic & Exponential & Hyperbolic & Quasi-hyperbolic \\
\hline \multicolumn{7}{|l|}{ (2) Patients } \\
\hline \multirow[t]{2}{*}{$\mu$} & $0.0036^{* * *}$ & $0.0042^{* * *}$ & $0.0035^{* * *}$ & $0.0044^{* * *}$ & $0.0052^{* * *}$ & $0.0048^{* * *}$ \\
\hline & $(0.0002)$ & $(0.0003)$ & $(0.0003)$ & $(0.0003)$ & $(0.0004)$ & $(0.0004)$ \\
\hline \multirow[t]{2}{*}{$r$} & $0.0215^{* * *}$ & $0.0338^{* * *}$ & $0.0233^{* * *}$ & $0.0279^{* * *}$ & $0.0465^{* * *}$ & $0.0225^{* * *}$ \\
\hline & $(0.0029)$ & $(0.0054)$ & $(0.0031)$ & $(0.0040)$ & $(0.0078)$ & $(0.0033)$ \\
\hline \multirow[t]{2}{*}{$\mathrm{b}$} & & & $1.0445^{* * *}$ & & & $0.8829^{* * * *}$ \\
\hline & & & $(0.0635)$ & & & $(0.0548)$ \\
\hline Observations & 7605 & 7605 & 7605 & 4255 & 4255 & 4255 \\
\hline Adj R-squared & 0.5525 & 0.5535 & 0.5525 & 0.6290 & 0.6293 & 0.6298 \\
\hline \multicolumn{7}{|l|}{ (2) Doctors } \\
\hline \multirow[t]{2}{*}{$\mu$} & $0.0038^{* * *}$ & $0.0039^{* * * *}$ & $0.0036^{* * *}$ & $0.0055^{* * * *}$ & $0.0058^{* * *}$ & $0.0057^{* * *}$ \\
\hline & $(0.0006)$ & $(0.0006)$ & $(0.0006)$ & $(0.0009)$ & $(0.0009)$ & $(0.0009)$ \\
\hline \multirow[t]{2}{*}{$r$} & $0.0065^{* * *}$ & $0.0087^{* *}$ & $0.0071^{* * *}$ & $0.0082^{* * *}$ & $0.0115^{* * *}$ & $0.0077^{* * *}$ \\
\hline & $(0.0018)$ & $(0.0031)$ & $(0.0017)$ & $(0.0017)$ & $(0.0029)$ & $(0.0015)$ \\
\hline \multirow[t]{2}{*}{ B } & & & $1.0426^{* * *}$ & & & $0.9685^{* * *}$ \\
\hline & & & (0.1016) & & & $(0.0788)$ \\
\hline Observations & 1780 & 1780 & 1780 & 1405 & 1405 & 1405 \\
\hline Adj R-squared & 0.3878 & 0.3883 & 0.3880 & 0.4313 & 0.4321 & 0.4315 \\
\hline
\end{tabular}

Note: ${ }^{*} \mathrm{p}<0.1,{ }^{* *} \mathrm{p}<0.05,{ }^{* * *} \mathrm{p}<0.01$.

\section{Appendix: Supplementary material}

Supplementary data to this article can be found online at doi:10.1016/j.jhealeco.2016.10.001.

\section{References}

Ahlbrecht, M., Weber, M., 1997. An empirical study on intertemporal decision making under risk. Management Science 43, 813-826.

Ainslie, G., 1975. Specious reward: a behavioral theory of impulsiveness and impulse control. Psychological Bulletin 82, 463.

Allison, J.J., Kiefe, C.I., Cook, E.F., Gerrity, M.S., Orav, E.J., Centor, R., 1998. The association of physician attitudes about uncertainty and risk taking with resource use in a Medicare HMO. Medical Decision Making: An International Journal of the Society for Medical Decision Making 18, 320-329.

Anderhub, V., Güth, W., Gneezy, U., Sonsino, D., 2001. On the interaction of risk and time preferences: an experimental study. German Economic Review 2, 239-253.

Andersen, S., Harrison, G.W., Lau, M.I., Rutström, E.E., 2008a. Lost in state space: are preferences stable? International Economic Review 49, 1091-1112.

Andersen, S., Harrison, G.W., Lau, M.I., Rutström, E.E., 2008b. Eliciting risk and time preferences. Econometrica: Journal of the Econometric Society 76, 583-618. doi:10.1111/j.1468-0262.2008.00848.x.

Andersen, S., Harrison, G.W., Lau, M.I., Rutström, E.E., 2010. Behavioral econometrics for psychologists. Journal Of Economic Psychology 31, 553-576.

Andersen, S., Harrison, G.W., Lau, M.I., Rutström, E.E., 2013. Discounting behaviour and the magnitude effect: evidence from a field experiment in Denmark. Economica 80, 670-697. doi:10.1111/ecca.12028.

Andersen, S., Harrison, G.W., Lau, M.I., Rutström, E.E., 2014. Discounting behavior: a reconsideration. European Economic Review 71, 15-33.

Anderson, L.R., Mellor, J.M., 2008. Predicting health behaviors with an experimental measure of risk preference. Journal of Health Economics 27, 1260-1274.
Andreoni, J., Sprenger, C., 2012. Risk preferences are not time preferences. The American Economic Review 102, 3357-3376.

Angeletos, G.-M., Laibson, D., Repetto, A., Tobacman, J., Weinberg, S., 2001. The hyperbolic consumption model: calibration, simulation, and empirical evaluation. Journal of Economic Perspectives: A Journal of the American Economic Association 15, 47-68.

Atanasov, P., Anderson, B.L., Cain, J., Schulkin, J., Dana, J., 2013. Comparing physicians personal prevention practices and their recommendations to patients. Journal for Healthcare Quality doi:10.1111/jhq.12042.

Attema, A.E., 2012. Developments in time preference and their implications for medical decision making. Journal of the Operational Research Society 63 , 1388-1399.

Attema, A.E., Bleichrodt, H., Rohde, K.I., Wakker, P.P., 2010. Time-tradeoff sequences for analyzing discounting and time inconsistency. Management Science 56, 2015-2030.

Axon, R.N., Bradford, W.D., Egan, B.M., 2009. The role of individual time preferences in health behaviors among hypertensive adults: a pilot study. Journal of the American Society of Hypertension 3, 35-41.

Barseghyan, L., Prince, J., Teitelbaum, J.C., 2011. Are risk preferences stable across contexts? Evidence from insurance data. The American Economic Review 101, 591-631.

Barsky, R.B., Kimball, M.S., Juster, F.T., Shapiro, M.D., 1995. Preference parameters and behavioral heterogeneity: an experimental approach in the health and retirement survey. National Bureau of Economic Research 112, 537-579.

Battalio, R.C., Kagel, J.H., Jiranyakul, K., 1990. Testing between alternative models of choice under uncertainty: some initial results. Journal of Risk and Uncertainty $3,25-50$.

Becker, G.S., Mulligan, C.B., 1997. The endogenous determination of time preference The Quarterly Journal of Economics 112, 729-758.

Beisswanger, A.H., Stone, E.R., Hupp, J.M., Allgaier, L., 2003. Risk taking in relationships: differences in deciding for oneself versus for a friend. Basic and Applied Social Psychology 25, 121-135.

Benhabib, J., Bisin, A., Schotter, A., 2010. Present-bias, quasi-hyperbolic discounting, and fixed costs. Games and Economic Behavior 69, 205-223. 
Benzion, U., Rapoport, A., Yagil, J., 1989. Discount rates inferred from decisions: an experimental study. Management Science 35, 270-284.

Bjerrum, L., Hamm, L., Toft, B., Munck, A., Kragstrup, J., 2002. Do general practitioner and patient agree about the risk factors for ischaemic heart disease? Scandinavian Journal of Primary Health Care 20, 16-21.

Blackburn, M., Harrison, G.W., Rutström, E.E., 1994. Statistical bias functions and informative hypothetical surveys. American Journal of Agricultural Economics 76, 1084-1088

Blais, A.-R., Weber, E.U., 2006. A domain-specific risk-taking (DOSPERT) scale for adult populations. Judgment and Decision Making 1, 33-47.

Bleichrodt, H., Johannesson, M., 2001. Time preference for health: a test of stationarity versus decreasing timing aversion. Journal of Mathematical Psychology 45, 265-282.

Bleichrodt, H., Wakker, P., Johannesson, M., 1997. Characterizing QALYs by risk neutrality. Journal of Risk and Uncertainty 15, 107-114.

Bleichrodt, H., Gao, Y., Rohde, K.I., 2014. Decreasing impatience for health and money.

Borghans, L., Golsteyn, B.H., 2006. Time discounting and the body mass index: evidence from the Netherlands. Economics and Human Biology 4, 39-61.

Bradford, D., Courtemanche, C., Heutel, G., McAlvanah, P., Ruhm, C., 2014. Time preferences and consumer behavior. National Bureau of Economic Research doi:10.3386/w20320.

Bradford, W.D., 2010. The association between individual time preferences and health maintenance habits. Medical Decision Making: An International Journal of the Society for Medical Decision Making 30, 99-112.

Bradford, W.D., Zoller, J., Silvestri, G.A., 2010. Estimating the effect of individual time preferences on the use of disease screening. Southern Economic Journal 76, 1005-1031.

Brandt, S., Dickinson, B., 2013. Time and risk preferences and the use of asthma controller medication. Pediatrics 131, e1204-e1210. doi:10.1542/peds.2011-2982.

Burks, S., Carpenter, J., Götte, L., Rustichini, A., 2012. Which measures of time preference best predict outcomes: evidence from a large-scale field experiment. Journal of Economic Behavior and Organization 84, 308-320. doi:10.1016/ j.jebo.2012.03.012.

Butler, S., Rosman, A., Seleski, S., Garcia, M., Lee, S., Barnes, J., Schwartz, A., 2012. A medical risk attitude subscale for DOSPERT.

Cairns, J., Van der Pol, M., 1997. Constant and decreasing timing aversion for saving lives. Social Science and Medicine 45, 1653-1659.

Cairns, J.A., 1994. Valuing future benefits. Health Economics 3, 221-229.

Chabris, C.F., Laibson, D., Morris, C.L., Schuldt, J.P., Taubinsky, D., 2008. Individual laboratory-measured discount rates predict field behavior. Journal of Risk and Uncertainty 37, 237-269.

Chapman, G.B., 1996. Temporal discounting and utility for health and money. Journal of Experimental Psychology. Learning, Memory, and Cognition 22, 771.

Chapman, G.B., Coups, E.J., 1999. Time preferences and preventive health behavior acceptance of the influenza vaccine. Medical Decision Making: An International Journal of the Society for Medical Decision Making 19, 307-314.

Chapman, G.B., Elstein, A.S., 1995. Valuing the future temporal discounting of health and money. Medical Decision Making: An International Journal of the Society for Medical Decision Making 15, 373-386.

Chapman, G.B., Brewer, N.T., Coups, E.J., Brownlee, S., Leventhal, H., Levanthal, E.A., 2001. Value for the future and preventive health behavior. Journal of Experimental Psychology. Applied 7, 235.

Charness, G., Gneezy, U., Imas, A., 2013a. Experimental methods: eliciting risk preferences. Journal of Economic Behavior and Organization 87, 43-51.

Charness, G., Gneezy, U., Kuhn, M.A., 2013b. Experimental methods: extra-laboratory experiments-extending the reach of experimental economics. Journal of Economic Behavior and Organization 91, 93-100.

Chesson, H., Viscusi, W.K., 2000. The heterogeneity of time-risk tradeoffs. Journal of Behavioral Decision Making 13, 251-258.

Coble, K.H., Lusk, J.L., 2010. At the nexus of risk and time preferences: an experimental investigation. Journal of Risk and Uncertainty 41, 67-79.

Cooper, L.A., Roter, D.L., Johnson, R.L., Ford, D.E., Steinwachs, D.M., Powe, N.R., 2003 Patient-centered communication, ratings of care, and concordance of patient and physician race. Annals of Internal Medicine 139, 907-915.

Cooper-Patrick, L., Gallo, J.J., Gonzales, J.J., Vu, H.T., Powe, N.R., Nelson, C., Ford, D.E. 1999. Race, gender, and partnership in the patient-physician relationship. JAMA: The Journal of the American Medical Association 282, 583-589.

Croson, R., Gneezy, U., 2009. Gender differences in preferences. Journal of Economic Literature 47, 448-474.

Cubitt, R.P., Read, D., 2007. Can intertemporal choice experiments elicit time preferences for consumption? Experimental Economics 10, 369-389.

Cummings, R.G., Harrison, G.W., Rutström, E.E., 1995. Homegrown values and hypothetical surveys: is the dichotomous choice approach incentive-compatible? The American Economic Review 85, 260-266.

Cummings, R.G., Elliott, S., Harrison, G.W., Murphy, J., 1997. Are hypothetical referenda incentive compatible? Journal of Political Economy 105, 609-621.

DellaVigna, S., Malmendier, U., 2006. Paying not to go to the gym. The American Economic Review 96, 694-719.

Diamond, P., Köszegi, B., 2003. Quasi-hyperbolic discounting and retirement. Journal of Public Economics 87, 1839-1872.

Dohmen, T., Falk, A., Huffman, D., Sunde, U., Schupp, J., Wagner, G.G., 2011. Individual risk attitudes: measurement, determinants, and behavioral consequences. Journal of the European Economic Association 9, 522-550.

Dolan, P., Gudex, C., 1995. Time preference, duration and health state valuations. Health Economics 4, 289-299.
Donkers, B., Melenberg, B., Van Soest, A., 2001. Estimating risk attitudes using lotteries: a large sample approach. Journal of Risk and Uncertainty 22, 165-195.

Dudley, N., 2001. Importance of risk communication and decision making in cardiovascular conditions in older patients: a discussion paper. Quality in Health Care 10, i19-i22.

Edwards, A., Elwyn, G., Wood, F., Atwell, C., Prior, L., Houston, H., 2005. Shared decision making and risk communication in practice: a qualitative study of GPs experiences. The British Journal of General Practice 55, 6-13.

Edwards, A., Gray, J., Clarke, A., Dundon, J., Elwyn, G., Gaff, C., Hood, K., Iredale, R., Sivell, S., Shaw, C., Thornton, H., 2008. Interventions to improve risk communication in clinical genetics: systematic review. Patient Education and Counseling 71, 4-25.

Edwards, A.G., Evans, R., Hood, K., Elwyn, G.J., 2006. Personalised risk communication for informed decision making about taking screening tests. Cochrane Library (2) CD001865.

Einav, L., Finkelstein, A., Pascu, I., Cullen, M., 2010. How general are risk preference? Choices under uncertainty in different domains. National Bureau of Economic Research 102, 2606-2638.

Epstein, L.G., Zin, S.E., 1989a. Substitution, risk aversion, and the temporal behavior of consumption and asset returns: a theoretical framework. Econometrica: Journal of the Econometric Society 57, 937-969.

Epstein, L.G., Zin, S.E., 1989b. Substitution, risk aversion, and the temporal behavior of consumption and asset returns: a theoretical framework. Econometrica: Journal of the Econometric Society 57, 937-969. doi:10.2307/1913778.

Fagerlin, A., Wang, C., Ubel, P.A., 2005a. Reducing the influence of anecdotal reasoning on people's health care decisions: is a picture worth a thousand statistics? Medical Decision Making: An International Journal of the Society for Medical Decision Making 25, 398-405.

Fagerlin, A., Zikmund-Fisher, B.J., Ubel, P.A., 2005b. Cure me even if it kills me: preferences for invasive cancer treatment. Medical Decision Making: An International Journal of the Society for Medical Decision Making 25, 614-619.

Fagerlin, A., Zikmund-Fisher, B.J., Ubel, P.A., 2005c. How making a risk estimate can change the feel of that risk: shifting attitudes toward breast cancer risk in a general public survey. Patient Education and Counseling 57, 294-299.

Fagerlin, A., Zikmund-Fisher, B.J., Ubel, P.A., 2011. Helping patients decide: ten steps to better risk communication. Journal of the National Cancer Institute 103 . 1436-1443.

Finucane, M.L., Alhakami, A., Slovic, P., Johnson, S.M., 2000. The affect heuristic in judgments of risks and benefits. Journal of Behavioral Decision Making 13, 1-17.

Fiscella, K., Franks, P., Zwanziger, J., Mooney, C., Sorbero, M., Williams, G.C., 2000 Risk aversion and costs: a comparison of family physicians and general internists. Journal of Family Practice 49, 12-17.

Franks, P., Williams, G.C., Zwanziger, J., Mooney, C., Sorbero, M., 2000. Why do physicians vary so widely in their referral rates? Journal of General Internal Medicine 15, 163-168.

Frederick, S., Loewenstein, G., O'Donoghue, T., 2002. Time discounting and time preference: a critical review. Journal of Economic Literature 40, 351-401.

Gafni, A., Torrance, G.W., 1984. Risk attitude and time preference in health. Management Science 30, 440-451.

Galizzi, M.M., Miraldo, M., 2012. Are you what you eat? Experimental evidence on risk preferences and health habits [WWW Document]. <http://wwwf.imperial .ac.uk/> (accessed 30.03.15.)

Galizzi, M.M., Miraldo, M., Stavropoulou, C., 2016. In sickness but not in wealth: field evidence on patients risk preferences in financial and health domains. Medical Decision Making: An International Journal of the Society for Medical Decision Making 36, 503-517. doi:10.1177/0272989X15626406.

Garcia-Retamero, R., Galesic, M., 2012. Doc, what would you do if you were me? On self-other discrepancies in medical decision making. Journal of Experimental Psychology. Applied 18, 38.

Garcia-Retamero, R., Galesic, M., 2014. On defensive decision making: how doctors make decisions for their patients. Health Expectations 17, 664-669. doi:10.1111/ j.1369-7625.2012.00791.x

Goto, R., Takahashi, Y., Nishimura, S., Ida, T., 2009. A cohort study to examine whether time and risk preference is related to smoking cessation success. Addiction (Abingdon, England) 104, 1018-1024.

Green, L., Myerson, J., McFadden, E., 1997. Rate of temporal discounting decreases with amount of reward. Memory \& Cognition 25, 715-723. doi:10.3758 BF03211314.

Greenfield, S., Kaplan, S., Ware, J.E., 1985. Expanding patient involvement in care: effects on patient outcomes. Annals of Internal Medicine 102, 520-528.

Gruber, J., Köszegi, B., 2001. Is addiction "rational"? Theory and evidence. The Quarterly Journal of Economics 116, 1261-1303. doi:10.1162/003355301753265570.

Gruber, J., Köszegi, B., 2004. Tax incidence when individuals are time-inconsistent: the case of cigarette excise taxes. Journal of Public Economics 88, 1959-1987.

Gurmankin, A.D., Baron, J., Hershey, J.C., Ubel, P.A., 2002. The role of physicians recommendations in medical treatment decisions. Medical Decision Making 22, 262-271.

Hanoch, Y., Johnson, J.G., Wilke, A., 2006. Domain specificity in experimental measures and participant recruitment an application to risk-taking behavior. Psychological Science 17, 300-304.

Hardisty, D.J., Weber, E.U., 2009. Discounting future green: money versus the environment. Journal of Experimental Psychology. General 138, 329.

Harrison, G.W., List, J.A., 2004. Field experiments. Journal of Economic Literature 42, 1009-1055.

Harrison, G.W., Rutström, E.E., 2008a. Experimental evidence on the existence of hypothetical bias in value elicitation methods. In: Plot, C.R., Smith, V.L. (Eds.), 
Handbook of Experimental Economics Results, vol. 1. North-Holland, Amsterdam, pp. 752-767.

Harrison, G.W., Rutström, E.E., 2008b. Risk aversion in the laboratory. In: Cox, J.C., Harrison, G.W. (Eds.), Risk Aversion in Experiments, vol. 12. Emerald Research in Experimental Economics, Bingley, UK.

Harrison, G.W., Johnson, E., McInnes, M.M., Rutström, E.E., 2005a. Risk aversion and incentive effects: comment. The American Economic Review 95, 897-901. doi: $10.1257 / 0002828054201378$.

Harrison, G.W., List, J.A., Towe, C., 2007. Naturally occurring preferences and exogenous laboratory experiments: a case study of risk aversion. Econometrica: Journal of the Econometric Society 75, 433-458.

Harrison, G.W., Lau, M.I., Rutström, E.E., 2009. Risk attitudes, randomization to treatment, and self-selection into experiments. Journal of Economic Behavior and Organization 70, 498-507.

Harrison, J.D., Young, J.M., Butow, P., Salkeld, G., Solomon, M.J., 2005b. Is it worth the risk? A systematic review of instruments that measure risk propensity for use in the health setting. Social Science and Medicine 60, 1385-1396.

Harvey, C., 1995. Proportional discounting of future costs and benefits. Mathematics of Operations Research 20, 381-399.

Harvey, C.M., 1986. Value functions for infinite-period planning. Management Science 32, 1123-1139.

Hershey, J.C., Schoemaker, P.J., 1980. Risk taking and problem context in the domain of losses: an expected utility analysis. Journal of Risk and Insurance 40, 111-132.

Holt, C.A., Laury, S.K., 2002. Risk aversion and incentive effects. The American Economic Review 92, 1644-1655.

Holt, C.A., Laury, S.K., 2005. Risk aversion and incentive effects: new data without order effects. The American Economic Review 95, 902-904.

Holtgrave, D.R., Lawler, F., Spann, S.J., 1991. Physicians' risk attitudes, laboratory usage, and referral decisions: the case of an academic family practice center. Medical Decision Making: An International Journal of the Society for Medical Decision Making 11, 125-130.

Iizuka, T., 2007. Experts' agency problems: evidence from the prescription drug market in Japan. The Rand Journal of Economics 38, 844-862.

Ikeda, S., Kang, M.-I., Ohtake, F., 2010. Hyperbolic discounting, the sign effect, and the body mass index. Journal of Health Economics 29, 268-284.

Jackson, D.N., Hourany, L., Vidmar, N.J., 1972. A four-dimensional interpretation of risk taking. Journal of Personality 40, 483-501.

Kipp, R., Lehman, J., Israel, J., Edwards, N., Becker, T., Raval, A.N., 2013. Patient preferences for coronary artery bypass graft surgery or percutaneous intervention in multivessel coronary artery disease. Catheterization and Cardiovascular Interventions 82, 212-218.

Kirby, K.N., Maraković, N.N., 1995. Modeling myopic decisions: evidence for hyperbolic delay-discounting within subjects and amounts. Organizational Behavior and Human Decision Processes 64, 22-30. doi:10.1006/obhd.1995.1086.

Kirby, K.N., Maraković, N.N., 1996. Delay-discounting probabilistic rewards: rates decrease as amounts increase. Psychonomic Bulletin \& Review 3, 100-104. doi:10.3758/BF03210748.

Kirby, K.N., Petry, N.M., Bickel, W.K., 1999. Heroin addicts have higher discount rates for delayed rewards than non-drug-using controls. Journal of Experimental Psychology. General 128, 78-87.

Kreps, D.M., Porteus, E.L., 1978. Temporal resolution of uncertainty and dynamic choice theory. Econometrica: Journal of the Econometric Society 46, 185-200.

Laibson, D., 1997. Golden eggs and hyperbolic discounting. The Quarterly Journal of Economics 112, 443-477.

Laury, S.K., McInnes, M.M., Swarthout, J.T., 2012. Avoiding the curves: direct elicitation of time preferences. Journal of Risk and Uncertainty 44, 181-217.

Loewenstein, G., Prelec, D., 1992. Anomalies in intertemporal choice: evidence and an interpretation. The Quarterly Journal of Economics 107, 573-597.

MacCrimmon, K.R., Wehrung, D.A., 1990. Characteristics of risk taking executives. Management Science 36, 422-435

Masclet, D., Colombier, N., Denant-Boemont, L., Loheac, Y., 2009. Group and individual risk preferences: a lottery-choice experiment with self-employed and salaried workers. Journal of Economic Behavior and Organization 70, 470-484

Mazur, J.E., 1987. An adjusting procedure for studying delayed reinforcement. In: Commons, M.L., Mazur, J.E., Nevin, J.A., Rachlin, H. (Eds.), Quantitative Analyses of Behavior: The Effect of Delay and of Intervening Events on Reinforcement Value, vol. 5. Erlbaum, London, pp. 55-73.

McClure, S.M., Laibson, D.I., Loewenstein, G., Cohen, J.D., 2004. Separate neural systems value immediate and delayed monetary rewards. Science 306, 503-507.

McGuire, T.G., 2000. Physician agency. In: Culyer, A.J., Newhouse, J.P. (Eds.), Handbook of Health Economics, vol. 1. Elsevier Science, Amsterdam, pp. 461-536.

Noussair, C., Wu, P., 2006. Risk tolerance in the present and the future: an experimental study. Managerial and Decision Economics 27, 401-412.

O’Donoghue, T., Rabin, M., 1999. Doing it now or later. The American Economic Review 89, 103-124.

Onay, S., Öncüler, A., 2007. Intertemporal choice under timing risk: an experimental approach. Journal of Risk and Uncertainty 34, 99-121.

Ortendahl, M., Fries, J.F., 2006. Discounting and risk characteristics in clinical decision-making. Medical Science Monitor 12, RA41-RA45.

Peele, P.B., Siminoff, L.A., Xu, Y., Ravdin, P.M., 2005. Decreased use of adjuvant breast cancer therapy in a randomized controlled trial of a decision aid with individualized risk information. Medical Decision Making: An International Journal of the Society for Medical Decision Making 25, 301-307.

Phelps, E.S., Pollak, R.A., 1968. On second-best national saving and game-equilibrium growth. The Review of Economic Studies 35, 185-199.
Picone, G., Sloan, F., Taylor, D., Jr., 2004. Effects of risk and time preference and expected longevity on demand for medical tests. Journal of Risk and Uncertainty 28, 39-53.

Prelec, D., 2004. Decreasing impatience: a criterion for non-stationary time preference and "hyperbolic" discounting. The Scandinavian Journal of Economics 106, 511-532.

Prosser, L.A., Wittenberg, E., 2007. Do risk attitudes differ across domains and respondent types? Medical Decision Making: An International Journal of the Society for Medical Decision Making 27, 281-287.

Rohde, K.I., 2010. The hyperbolic factor: a measure of time inconsistency. Journal of Risk and Uncertainty 41, 125-140.

Saha, S., Komaromy, M., Koepsell, T.D., Bindman, A.B., 1999. Patient-physician racia concordance and the perceived quality and use of health care. Archives of Internal Medicine 159, 997-1004.

Samuelson, P., 1947. Foundations of Economic Analysis. Harvard University Press, Cambridge, MA.

Say, R.E., Thomson, R., 2003. The importance of patient preferences in treatment decisions - challenges for doctors. BMJ (Clinical Research Ed.) 327, 542-545.

Scholten, M., Read, D., 2010. The psychology of intertemporal tradeoffs. Psychological Review 117, 925-944. doi:10.1037/a0019619.

Sloan, F.A., Eldred, L.M., Xu, Y., 2014. The behavioral economics of drunk driving. Journal of Health Economics 35, 64-81. doi:10.1016/j.jhealeco.2014.01.005.

Stavropoulou, C., 2012. The doctor-patient relationship: a review of the theory and policy implications. In: The LSE Companion to Health Policy. Edward Elgar Publishing Ltd, Cheltenham, pp. 314-326.

Stevenson, M.K., 1992. The impact of temporal context and risk on the judged value of future outcomes. Organizational Behavior and Human Decision Processes 52, 455-491.

Strotz, R.H., 1955. Myopia and inconsistency in dynamic utility maximization. The Review of Economic Studies 23, 165-180. doi:10.2307/2295722.

Sutter, M., Kocher, M.G., Rützler, D., Trautmann, S., 2011. Impatience and uncertainty: Experimental decisions predict adolescents' field behavior.

Sutter, M., Kocher, M.G., Glätzle-Reützler, D., Trautmann, S.T., 2013. Impatience and uncertainty: experimental decisions predict adolescents' field behavior. The American Economic Review 103, 510-531. doi:10.1257/aer.103.1.510.

Szrek, H., Chao, L.-W., Ramlagan, S., Peltzer, K., 2012. Predicting (un) healthy behavior: a comparison of risk-taking propensity measures. Judgment and Decision Making $7,716$.

Tanaka, T., Camerer, C.F., Nguyen, Q., 2010. Risk and time preferences: linking experimental and household survey data from Vietnam. The American Economic Review 100, 557-571.

Thaler, R., 1981. Some empirical evidence on dynamic inconsistency. Economics Letters 8, 201-207. doi:10.1016/0165-1765(81)90067-7.

Ubel, P.A., Angott, A.M., Zikmund-Fisher, B.J., 2011. Physicians recommend different treatments for patients than they would choose for themselves. Archives of Internal Medicine 171, 630-634.

van der Pol, M., Cairns, J., 2001. Estimating time preferences for health using discrete choice experiments. Social Science and Medicine 52, 1459-1470.

van der Pol, M., Cairns, J., 2002. A comparison of the discounted utility model and hyperbolic discounting models in the case of social and private intertemporal preferences for health. Journal of Economic Behavior and Organization 49, 79 96.

van der Pol, M., Cairns, J., 2008. Comparison of two methods of eliciting time preference for future health states. Social Science and Medicine 67, 883-889.

van der Pol, M., Ruggeri, M., 2008. Is risk attitude outcome specific within the health domain? Journal of Health Economics 27, 706-717.

Van Der Pol, M., 2011. Health, education and time preference. Health Economics 20, 917-929.

Van Der Pol, M., Cairns, J., 1999. Individual time preferences for own health: an application of a dichotomous choice question with follow-up. Applied Economics Letters 6, 649-654.

Vischer, T., Dohmen, T., Falk, A., Huffman, D., Schupp, J., Sunde, U., Wagner, G.G., 2013. Validating an ultra-short survey measure of patience. Economics Letters 120 , 142-145.

Viscusi, W.K., Evans, W.N., 1990. Utility functions that depend on health status: estimates and economic implications. The American Economic Review 80, 353-374.

Waldron, C.-A., Gallacher, J., van der Weijden, T., Newcombe, R., Elwyn, G., 2010. The effect of different cardiovascular risk presentation formats on intentions, understanding and emotional affect: a randomised controlled trial using a web-based risk formatter (protocol). BMC Medical Informatics and Decision Making 10, 41.

Weber, B.J., Chapman, G.B., 2005. The combined effects of risk and time on choice: does uncertainty eliminate the immediacy effect? Does delay eliminate the certainty effect? Organizational Behavior and Human Decision Processes 96, 104-118.

Weber, E.U., Blais, A.-R., Betz, N.E., 2002. A domain-specific risk-attitude scale: measuring risk perceptions and risk behaviors. Journal of Behavioral Decision Making 15, 263-290.

Weller, R.E., Cook, E.W., Avsar, K.B., Cox, J.E., 2008. Obese women show greater delay discounting than healthy-weight women. Appetite 51, 563-569.

WHO, 2003. Adherence to long-term therapies: evidence for action.

Zikmund-Fisher, B.J., Fagerlin, A., Ubel, P.A., 2004. “Is 28\% good or bad?” Evaluability and preference reversals in health care decisions. Medical Decision Making: An International Journal of the Society for Medical Decision Making 24, 142-148. 